\title{
Biomonitoring for assessment of organic dust-induced lung inflammation
}

\author{
L.J. Mueller-Anneling, M.E. O'Neill and P.S. Thorne
}

\begin{abstract}
Inhalation exposure to particulate matter containing endotoxin (or lipopolysaccharide (LPS)) occurs in a variety of occupations. Nasal lavage and induced sputum have been used to evaluate lung inflammation resulting from such exposures. Whole blood assay (WBA) measures cytokine production of leukocytes after ex vivo stimulation with LPS. The present study examined the effectiveness of WBA for evaluating inflammatory responses and susceptibility.

C3HeB/FEJ mice were tolerised by LPS injection or sham tolerised with saline. Animals then inhaled either swine barn dust extract containing endotoxin or saline. Bronchoalveolar lavage (BAL) fluid was assayed for leukocyte counts and pro-inflammatory cytokines (interleukin-6, tumour necrosis factor- $\alpha$ ). Whole blood was stimulated with 10 or $100 \mathrm{ng} \cdot \mathrm{mL}^{-1}$ of LPS, incubated for 5 or $18 \mathrm{~h}$ and assayed for cytokines.

Barn dust-exposed groups revealed significantly higher total cells, neutrophils and cytokines in BAL compared with saline-exposed groups. Animals tolerised to LPS and exposed to barn dust demonstrated lower cellular and cytokine BAL responses. Similarly, WBA yielded significantly elevated cytokines with barn dust exposure and reduced responses with tolerisation.

This study demonstrates the efficacy of whole blood assay as a biomarker of inhalation exposure to inflammatory agents and its use for assessing susceptibility to organic dust-induced lung inflammation.
\end{abstract}

KEYWORDS: Biomonitoring, endotoxin, exposure assessment, organic dust, whole blood assay

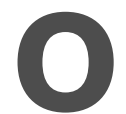
rganic dust is a complex bio-aerosol consisting of bacterial and fungal products and their metabolites, animal, insect, and plant components. Inhalation of organic dust may cause severe acute pulmonary and systemic inflammation and lead to occupational asthma and other obstructive pulmonary diseases [1, 2]. Studies have shown that a nonallergic, neutrophilmediated response accounts for these pulmonary health outcomes and that pro-inflammatory cytokines, such as tumour necrosis factor (TNF)- $\alpha$, interleukin (IL)-1 $\beta$ and IL-6, play a major role in the inflammatory process [2-4]. A significant component of organic dust responsible for lung inflammation is endotoxin, also referred to as lipopolysaccharide (LPS). Endotoxin exposure is associated with adverse respiratory effects in the indoor environment [5] and is a well-recognised occupational hazard in: 1) swine, poultry and dairy barns; 2) grain handling facilities; 3 ) vegetable and cotton processing; 4) sawmills, metal machining, fibreglass production operations; and 5) composting and waste handling [6]. Endotoxin forms the exterior layer of the outer cell membrane of nearly all Gram-negative bacteria and is known to have potent pro-inflammatory effects attributed to the lipid-A region of the molecule [7-9]. Since this region is imbedded in the bacterial cell membrane, endotoxin is most potent when released by intact cells or upon disruption of the membrane [10].

Studies have demonstrated that a decline in forced expiratory volume in one second followassociated with increased production of inflammatory mediators by alveolar macrophages and peripheral blood monocytes [11]. It may therefore be possible to evaluate immune responses to organic dust-induced airway inflammation through analysis of the ex vivo release of cytokines by blood monocytes or alveolar macrophages. However, isolating and culturing these cells is time consuming and not conducive to studies of multiple subjects. In addition, isolated cells may not respond in the same manner as when maintained in their natural matrix. Although not a perfect substitute, an ex vivo whole blood assay (WBA) attempts to preserve various blood cell interactions necessary for cytokine response and cell viability and may be a suitable alternative $[12,13]$. Unlike nasal lavage or induced sputum production, the volume of blood used for the assay is invariable, which allows for the determination of accurate total cell ing endotoxin or organic dust exposure is
AFFILIATIONS

Dept of Occupational and

Environmental Health, University of lowa, lowa City, IA, USA.

CORRESPONDENCE

P.S. Thorne

Dept of Occupational and

Environmental Health

The University of lowa

College of Public Health

100 Oakdale Campus

IREH

lowa City

IA 52242-5000

USA

Fax: 13193354006

E-mail: peter-thorne@uiowa.edu

Received:

August 042004

Accepted after revision:

February 132006

SUPPORT STATEMENT

This research was supported by a pilot grant from the University of lowa, Environmental Health Sciences Research Center (NIEHS P30 ES05605). L.J. Mueller-Anneling was funded by a National Institutes of Health institutional training grant (NIEHS T32 ES07314).

Online ISSN 1399-3003 
counts. Several implementations of whole blood analysis have been used to examine immune responses to various agents and conditions, including pyrogens [14-16], sepsis [17, 18], infectious disease $[17,19,20]$, allergens [21, 22] and other environmental agents [23-25]. Using methods similar to this study, WOUTERs et al. [26] assessed within- and between-subject variation of the WBA in normal, unexposed volunteers and found that there was relatively low within-subject variance compared with between-subject variance, particularly for IL-1 $\beta$ and IL-6. Intra-individual variances for these two cytokines at LPS stimuli of 12.5 and $100 \mathrm{ng} \cdot \mathrm{mL}^{-1}$ were 0.15 and 0.18 for IL$1 \beta$ and 0.14 and 0.12 for IL-6, respectively. As with other studies, the whole blood responded in a dose-response relationship to the inflammatory agents LPS and curdlan. Of the four cytokines analysed, the greatest consistency of response was observed with IL-1 $\beta$ and IL-6 [26].

Previous research in the present authors' laboratory demonstrated that mice tolerised to endotoxin prior to organic dust exposure had a reduced pulmonary inflammatory response upon inhalation exposure to grain dust as compared to their naïve counterparts [27]. This phenomenon has been previously reported in the literature [28] and has been referred to as endotoxin or LPS "tolerance" or "adaptation" [2, 27, 29, 30]. The present study evaluates WBA response as a biomarker of exposure to organic dust and uses the endotoxin-tolerised mouse as a model for workers tolerised to endotoxin through daily occupational exposure. These experiments sought to test whether mice exposed to organic dust from swine confinement facilities have a more vigorous whole blood cytokine response to endotoxin than sham-exposed animals and if the cytokine response of mouse whole blood stimulated ex vivo increases with higher concentrations of endotoxin stimulant [31]. A second objective was to determine whether LPS tolerance led to reduced responsiveness as assessed using WBA.

\section{MATERIALS AND METHODS}

\section{Animals}

Male, 6-week-old C3HeB/FeJ mice (Jackson Labs, Bar Harbor, ME, USA) were housed in an American Association for Accreditation of Laboratory Animal Care-accredited rodent vivarium. All protocols were reviewed and approved by the Institutional Animal Care and Use Committee of the University of Iowa (Iowa City, IA, USA). Mice were quarantined for 12 days before the experiments were initiated. Four mice were reserved as sentinels and necropsied at the beginning and end of the experiment to verify animal health. Thirty-two mice were divided into two exposure groups: a sham exposure group, which received nebulised saline; and an organic dust exposure group, which was exposed to a nebulised extract of dust collected from a concentrated animal feeding operation (CAFO) housing swine (CAFO dust). The strain of mouse chosen for the current study has been previously characterised as "endotoxin sensitive" in an organic dust exposure model [27].

\section{Induced lipopolysaccharide tolerance}

Endotoxin tolerance was induced in half of the mice from each exposure group, as previously described [27, 32]. Briefly, mice received daily intraperitoneal (i.p.) injections of increasing doses of Escherichia coli O111:B4 endotoxin (Sigma, St Louis,
MO, USA) as follows. Day 1: $100 \mu \mathrm{g} \cdot \mathrm{kg}^{-1}$; day 2: $500 \mu \mathrm{g} \cdot \mathrm{kg}^{-1}$; day 3: $1,000 \mu \mathrm{g} \cdot \mathrm{kg}^{-1}$; day 4: $5,000 \mu \mathrm{g} \cdot \mathrm{kg}^{-1}$. Endotoxin concentration of the stock solution was confirmed by kinetic chromogenic Limulus amebocyte lysate (LAL) assay (BioWhittaker Inc., Walkersville, MD, USA). The remaining 16 control mice were administered pyrogen-free saline in a similar fashion.

\section{Swine CAFO dust extract}

Dust samples were obtained from an Eastern Iowa swine CAFO by vacuuming vertical surfaces with a sampling vacuum. An extract of the dust was prepared at a concentration of $100 \mathrm{mg} \cdot \mathrm{mL}^{-1}$ in sterile, physiological saline. The dust was eluted by first vortexing for 2 min and then shaking on a laboratory rotator for $1 \mathrm{~h}$ at ambient temperature. Insoluble particles were removed by centrifuging and decanting twice at $3,350 \times g$ for $15 \mathrm{~min}$ each. The final supernatant was adjusted to $\mathrm{pH} 7.2$.

\section{Exposure}

Mice were exposed in a whole-body exposure chamber [33] for $4 \mathrm{~h}$ to either nebulised saline $(\mathrm{n}=16)$ or nebulised CAFO dust extract $(n=16)$. In each exposure group, half of the mice were from the induced tolerance (LPS i.p.) group and the remaining were controls (saline i.p.). Aerosols were generated with a sixjet Collison nebuliser (BGI Inc., Waltham, MA, USA) with a $138-\mathrm{kPa}$ air supply [7]. Airflow through the chamber was regulated by an exhaust flow of $22.5 \mathrm{~L} \cdot \mathrm{min}^{-1}$. Passive airflow into the exposure chamber was filtered through an organic vapour cartridge and P100 particulate filter (North Safety Products, Cranston, RI, USA). Endotoxin concentration within the exposure chamber was measured by hourly collection of 15-min air samples collected on 47-mm glass fibre filters.

\section{Bronchoalveolar lavage fluid and whole blood collection}

At $1 \mathrm{~h}$ post-exposure $(5 \mathrm{~h}$ after the initiation of the inhalation exposure), animals were anaesthetised, euthanised and exsanguinated by cardiac puncture to obtain heparinised whole blood. Blood from all animals of an exposure group was pooled and held at $4^{\circ} \mathrm{C}$. Pooling of blood from individual mice was necessary to obtain sufficient blood for the WBA. Immediately following blood collection, bronchoalveolar lavage fluid (BALF) was obtained for total and differential cell counts and cytokine analyses. The lungs were lavaged with sterile, pyrogen-free saline at a pressure of $25 \mathrm{cmH}_{2} \mathrm{O}$ in 1-mL increments for a total volume of $4 \mathrm{~mL}$. BALF was stored at $4{ }^{\circ} \mathrm{C}$ and processed as soon as possible after collection. The BALF was centrifuged for $5 \mathrm{~min}$ at $200 \times g$ and the resulting supernatant was decanted, divided into equal volume aliquots and frozen at $-80^{\circ} \mathrm{C}$ for later cytokine analysis. The remaining cell pellet was re-suspended in RPMI media and prepared for total and differential cell counts. Total counts were performed using an improved Neubauer hemocytometer (Reichert, Buffalo, NY, USA), and the Diff Quick Stain Set (Harleco, Gibbstown, NY, USA) was used for staining for differential enumeration by microscopy.

\section{Whole blood assay}

Whole blood samples were pooled by endotoxin tolerance and exposure groups, and diluted with an equal volume of saline. The diluted whole blood was pipetted into tissue culture tubes 



FIGURE 1. a) Total cells, b) neutrophils, c) interleukin (IL)- 6 and tumour necrosis factor (TNF)- $\alpha$ in bronchoalveolar lavage fluid (BALF) from sham-tolerised (No tls) and tolerised (lipopolysaccharide (LPS) tls) mice exposed to saline (bars shaded green) and concentrated animal feeding operation dust (bars shaded yellow); sentinels are represented by orange shading. Error bars indicate mean \pm SEM. ${ }^{* *}: p<0.01 ;{ }^{* *}: p<0.001$.

in duplicate aliquots of $900 \mu \mathrm{L}$. To each of these tubes, $100 \mu \mathrm{L}$ of LPS was added to stimulate cytokine release as follows: high LPS stimulant $\left(100 \mathrm{ng} \cdot \mathrm{mL}^{-1}\right)$, low LPS stimulant $\left(10 \mathrm{ng} \cdot \mathrm{mL}^{-1}\right)$, and saline control. LPS was purchased from BioWhittaker Inc. as a lyophilised extract of E. coli serotype O55:B5. Tubes with blood and stimulant were incubated at $37^{\circ} \mathrm{C}$ at $95 \%$ humidity and $5 \%$ carbon dioxide in duplicate. Following either a 5- or 18-h incubation, $500 \mu \mathrm{L}$ saline was added to each tube before centrifugation at $1,000 \times g$ for $15 \mathrm{~min}$. The resulting plasma supernatants were decanted and stored at $-80^{\circ} \mathrm{C}$ until cytokine analysis.

\section{ELISA and Limulus amebocyte lysate assays}

Murine IL- 6 and TNF- $\alpha$ cytokine concentrations in bronchoalveolar lavage (BAL) supernatant and WBA plasma samples were determined using commercially available ELISA kits (BioSource International, Camarillo, CA, USA). Endotoxin concentrations of air filter samples were determined using kinetic chromogenic LAL assay, performed as previously described [7].

\section{Statistical methods}

Primary dependent variables included BAL total and differential cell counts, BALF cytokine concentrations, and WBA cytokine production with and without LPS stimulation. For the
WBA, net induced cytokine production was calculated by subtracting the nonstimulated control from the corresponding LPS stimulated result. Unpaired t-tests were used to analyse BALF data. Comparisons were considered significant at $p \leqslant 0.01$.

\section{RESULTS}

\section{Exposure}

The concentration of the endotoxin delivered in the CAFO dust extract exposure averaged $28.4 \pm 4.1 \mu \mathrm{g} \cdot \mathrm{m}^{-3}$. This concentration corresponds to a body burden of $490 \mathrm{ng} \cdot \mathrm{kg}^{-1}\left(4,900 \mathrm{EU} \cdot \mathrm{kg}^{-1}\right)$, which is $\sim 10$ times the lung burden a CAFO worker would amass over an 8-h working day in a CAFO operated without any exposure controls [34].

\section{Results of bronchoalveolar lavage fluid analysis}

Significantly higher total and neutrophil cell counts as well as cytokine concentrations were observed for both CAFO dustexposed groups as compared with the sham-exposed groups $(\mathrm{p}<0.001$; fig. 1). Mice exposed to CAFO dust had a far higher concentration of total BAL cells than the sham-exposed group mean $(\mathrm{p}<0.001$; fig. $1 \mathrm{a})$. This response was marked by an influx of neutrophils, resulting in an increase from $1 \%$ neutrophils in controls to $97 \%$ in CAFO dust-exposed mice. Figure $1 \mathrm{~b}$ illustrates that neutrophils increased in concentration from 230 

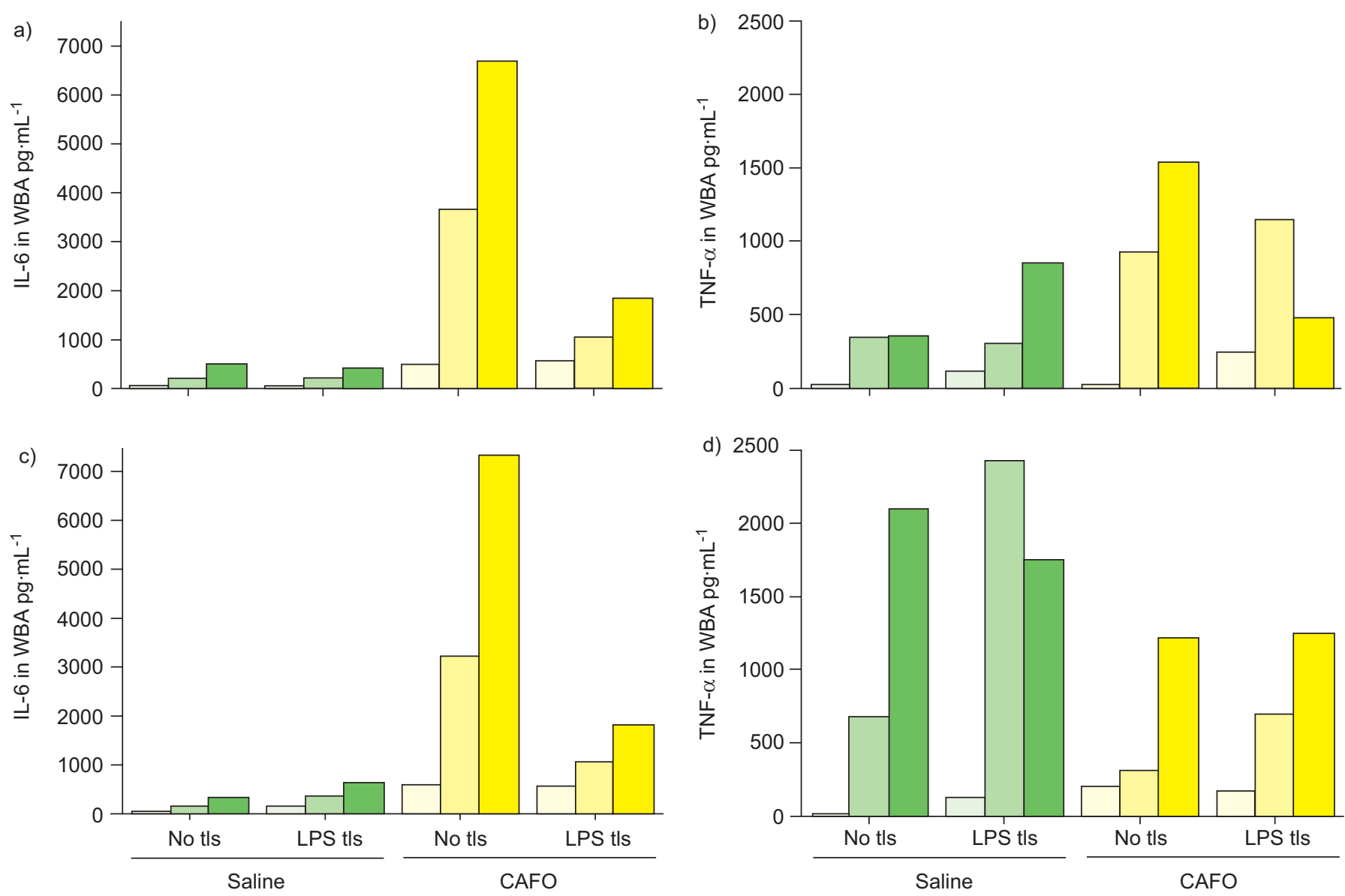

FIGURE 2. Whole blood analysis (WBA) cytokine results for a) interleukin (IL)- 6 and b) tumour necrosis factor (TNF)- $\alpha$ following 5-h incubation of the whole blood after lipopolysaccharide (LPS) stimulation and c) IL-6 and d) TNF- $\alpha$ following 18-h incubation. WBA from the saline (green bars) and concentrated animal feeding operation (CAFO; yellow) groups were either unstimulated (lightest bars), stimulated with low LPS (mid-shaded bars) or stimulated with high LPS (darkest bars). No tls: nontolerised; LPS tls: tolerised.

cells $\cdot \mathrm{mL}^{-1}$ in controls to $1,600,000$ cells $\cdot \mathrm{mL}^{-1}$ in the CAFO dustexposed mice.

Animals tolerised to LPS and exposed to CAFO dust had significantly lower BALF total cells $(1.13 \times 106$ versus $1.61 \times 106$ cells $\left.\cdot \mathrm{mL}^{-1} ; \quad \mathrm{p}<0.001\right)$ and neutrophils $(1.08 \times 106$ versus $1.59 \times 106$ cells $\left.\cdot \mathrm{mL}^{-1} ; \mathrm{p}<0.001\right)$ compared with animals that received the same exposure but without tolerisation (fig. 1a and $b$ ). Furthermore, as shown in figure 1c, tolerised animals in the CAFO dust-exposed group did not have as vigorous a pulmonary inflammatory response as the nontolerised animals, as measured by IL- 6 release $\left(3,400\right.$ versus $1,100 \mathrm{pg} \cdot \mathrm{mL}^{-1}$; $p<0.001)$. There was no difference in TNF- $\alpha$ between these two groups (fig. 1d). However, the TNF- $\alpha$ response was extremely high $\left(>17,000 \mathrm{pg} \cdot \mathrm{mL}^{-1}\right)$ for both the tolerised and nontolerised groups exposed to CAFO dust. There were no significant differences in pulmonary inflammatory responses between the control (sham-exposed) tolerised and nontolerised groups.

\section{Whole blood assay}

Results of the WBA on pooled blood from the animals described previously are shown in figure 2. The whole blood was incubated for either 5 or $18 \mathrm{~h}$ with no in vitro stimulation or stimulation with low or high amounts of LPS. In most cases, there was an increased release of cytokines in vitro with increasing endotoxin stimulation. Cytokine release was higher in non-tolerised CAFO dust-exposed mice than sham-exposed mice at the 5- and 18-h time points for IL- 6 but not TNF- $\alpha$. Tolerising animals to LPS prior to CAFO dust-extract exposure dramatically reduced their IL-6 response compared with the exposed, nontolerised animals for both the 5- and 18-h time points. As with BALF, this difference was not generally reflected in the sham-exposed groups. The pattern of responsiveness between exposure (sham versus CAFO dust) and tolerance (saline versus LPS) groups for TNF- $\alpha$ suggested a stronger response to LPS stimulation in the animals that were not exposed to CAFO dust. This may be due to the fact that TNF- $\alpha$ response among mice exposed to CAFO dust peaked before the 5-h time point.

\section{DISCUSSION}

Mice exposed to inhaled swine CAFO dust developed a profound lung inflammatory response as demonstrated by a 40 -fold increase in BALF cells (30-fold for the tolerised group), a 6,500-fold increase in neutrophils (8,500 for tolerised group) and a $\sim 250$-fold increase in two cytokines that serve as markers of inflammation: TNF- $\alpha$ and IL-6. Sham-exposed mice 
who breathed nebulised, pyrogen-free saline did not demonstrate any changes in these outcome variables as compared with sentinel animals.

The present study demonstrated that mice tolerised to endotoxin prior to inhalation exposure to swine CAFO dust have significantly fewer total cells and neutrophils in BALF. These mice also responded less vigorously in WBA than nontolerised mice receiving the same exposure. Differences in susceptibility between exposure groups were evident, as demonstrated by the greater WBA IL- 6 cytokine responses in both CAFO dust-exposed groups as compared with the shamexposed groups. The same effect was found to a lesser degree for TNF- $\alpha$ after 5-h WBA incubation but not 18-h incubation. It is possible this was due to the timing of the assay, since TNF- $\alpha$ production peaks much earlier than IL-6 [13]. Furthermore, in human WBA studies, TNF- $\alpha$ production has been found to be much more variable both within and between individuals [12, 26]. These data indicate that WBA functions as a biomarker assay of exposure effect and of reduced susceptibility due to induced tolerance, and suggest that IL- 6 might be a more reliable marker of this effect.

Endotoxin exposures were $\sim 10$-fold higher than would be experienced by CAFO workers [6,34]. Despite this difference in exposure used to elicit a response, WBA might also be applicable to human inhalation exposure studies. It is known that individuals vary in their response to inhalation of organic dusts and LPS in both occupational and experimental settings $[11,35]$. The nature of this difference may relate to factors in the pathway of signal transduction, from endotoxin to toll-like receptor (TLR)4 via LPS-binding protein, CD14 and MD2 [36]. Another significant factor may be genetic determinants of immune responses to LPS. TLR4 polymorphisms may account for some of this variability, but other genes also seem to play an important role [37-39]. ARBOUR et al. [40] found that two common TLR4 mutations (Asp299Gly and Thr399Ile) were associated with a decreased response to inhaled LPS in humans. Insertion of the wild-type allele into primary airway epithelial cell or alveolar macrophage cell cultures from individuals with the aforementioned TLR4 mutations could reverse this effect in vitro. Some of this variability may also depend on the type of endotoxin (cell-bound versus purified) present in the exposure [41] and pre-existing conditions such as asthma [42]. A whole blood in vitro stimulation assay attempts to account for this variability by maintaining an "intact" cellular milieu; it may therefore be a good predictor of an individual's immune response to various environmental and microbial agents [43].

Workers exposed to high endotoxin in CAFOs, in grain-dust or composting facilities, or in vegetable-washing operations may become tolerised to endotoxin. One way in which this is apparent is in "Monday morning fever" in cotton and textile workers, where those exposed to endotoxin early in the week (i.e. after a weekend off from work) have more significant respiratory symptoms than they do later in the week [44]. Data from this study suggest that cytokine production in the WBA for cotton would diminish over the course of the working week.

Several previous studies have sought to validate WBA [15, 16, $26,45]$. WOUTERs et al. [26] determined that between-individual variability in WBA with LPS and $\beta$-glucan stimulation was more significant than within-individual variability. WBA was a reliable, reproducible measure of an individual's responsiveness. However, that study used unexposed normal subjects so no inference could be made regarding the utility of WBA for biomonitoring exposures to inflammatory agents. Other studies have characterised LPS-induced cytokine responses of cultured cells, including monocytes and lymphocytes, but did not investigate WBA $[13,39,46]$. The role of occupationally induced LPS tolerance in WBA has not been adequately explored.

In conclusion, the present study in a murine inhalation exposure model suggests that whole blood analysis may serve as a biomarker of exposure and an alternative to various methods that are either nonspecific or more invasive and not applicable to large, population-based occupational exposure studies. Further research is needed in human exposure models to confirm these findings. One such study is currently underway in the present authors' laboratory.

\section{ACKNOWLEDGEMENTS}

The authors gratefully acknowledge the helpful suggestions of G. Doekes of Utrecht University (Utrecht, the Netherlands).

\section{REFERENCES}

1 American Thoracic Society. Respiratory health hazards in agriculture. Am J Respir Crit Care Med 1998; 158: S1-S76.

2 Rylander R. Endotoxin in the environment - exposure and effects. J Endotoxin Res 2002; 8: 241-252.

3 Clapp WD, Becker S, Quay J, et al. Grain dust-induced airflow obstruction and inflammation of the lower respiratory tract. Am J Respir Crit Care Med 1994; 150: 611-617.

4 Jagielo PJ, Thorne PS, Watt JL, Frees KL, Quinn TJ, Schwartz DA. Grain dust and endotoxin inhalation challenges produce similar inflammatory responses in normal subjects. Chest 1996; 110: 263-270.

5 Thorne PS, Kulhankova K, Yin M, Cohn R, Arbes SJ, Zeldin DC. Endotoxin exposure is a risk factor for asthma: the national survey of endotoxin in United States housing. Am J Respir Crit Care Med 2005; 172: 1371-1377.

6 Douwes J, Thorne P, Pearce N, Heederik D. Bioaerosol health effects and exposure assessment: progress and prospects. Ann Occup Hyg 2003; 47: 187-200.

7 Thorne PS. Inhalation toxicology models of endotoxin- and bioaerosol-induced inflammation. Toxicology 2000; 152: 13-23.

8 Wiese A, Brandenburg K, Ulmer AJ, Seydel U, MullerLoennies S. The dual role of lipopolysaccharide as effector and target molecule. Biol Chem 1999; 380: 767-784.

9 Thorn J. The inflammatory response in humans after inhalation of bacterial endotoxin: a review. Inflamm Res 2001; 50: 254-261.

10 Khan SA, Everest P, Servos S, et al. A lethal role for lipid A in Salmonella infections. Mol Microbiol 1998; 29: 571-579.

11 Kline JN, Cowden JD, Hunninghake GW, et al. Variable airway responsiveness to inhaled lipopolysaccharide. Am J Respir Crit Care Med 1999; 160: 297-303.

12 Ojeda Ojeda M, Silva CV, de J Arana Rosainz M, Fernandez-Ortega C. TNFalpha production in whole blood 
cultures from healthy individuals. Biochem Biophys Res Commun 2002; 292: 538-541.

13 Allen JN, Herzyk DJ, Allen ED, Wewers MD. Human whole blood interleukin-1-beta production: kinetics, cell source, and comparison with TNF-alpha. J Lab Clin Med 1992; 119: 538-546.

14 Poole S, Mistry Y, Ball C, et al. A rapid "one-plate" in vitro test for pyrogens. J Immunol Methods 2003; 274: 209-220.

15 Fennrich S, Fischer M, Hartung $T$, et al. Detection of endotoxins and other pyrogens using human whole blood. Dev Biol Stand 1999; 101: 131-139.

16 Hartung T, Wendel A. [Detection of pyrogens using human whole blood]. ALTEX 1995; 12: 70-75.

17 Rigato O, Salomao R. Impaired production of interferongamma and tumor necrosis factor-alpha but not of interleukin 10 in whole blood of patients with sepsis. Shock 2003; 19: 113-116.

18 Yaqub S, Solhaug V, Vang T, et al. A human whole blood model of LPS-mediated suppression of $\mathrm{T}$ cell activation. Med Sci Monit 2003; 9: BR120-BR126.

19 House D, Chinh NT, Hien TT, et al. Cytokine release by lipopolysaccharide-stimulated whole blood from patients with typhoid fever. J Infect Dis 2002; 186: 240-245.

20 Diterich I, Harter L, Hassler D, Wendel A, Hartung T. Modulation of cytokine release in ex vivo-stimulated blood from borreliosis patients. Infect Immun 2001; 69: 687-694.

21 Ellaurie M, Yost SL, Rosenstreich DL. A simplified human whole blood assay for measurement of dust mite-specific gamma interferon production in vitro. Ann Allergy 1991; 66: 143-147.

22 Kruger T, Sigsgaard T, Bonefeld-Jorgensen EC. Ex vivo induction of cytokines by mould components in whole blood of atopic and non-atopic volunteers. Cytokine 2004; 25: 73-84.

23 Sigsgaard T, Bonefeld-Jorgensen EC, Kjaergaard SK, Mamas S, Pedersen OF. Cytokine release from the nasal mucosa and whole blood after experimental exposures to organic dusts. Eur Respir J 2000; 16: 140-145.

24 Fennrich S, Zucker B, Hartung T. [A new application for the human whole blood test: development of an assay to assess the health risk of air-borne microbial contaminations]. ALTEX 2001; 18: 41-46.

25 Bønløkke JH, Thomassen M, Viskum S, Omland O, Bonefeld-Jorgensen E, Sigsgaard T. Respiratory symptoms and ex vivo cytokine release are associated in workers processing herring. Int Arch Occup Environ Health 2004; 77: 136-141.

26 Wouters IM, Douwes J, Thorne PS, Heederik D, Doekes G. Inter- and intraindividual variation of endotoxin- and beta(1 --> 3)-glucan-induced cytokine responses in a whole blood assay. Toxicol Ind Health 2002; 18: 15-27.

27 Schwartz DA, Thorne PS, Jagielo PJ, White GE, Bleuer SA, Frees KL. Endotoxin responsiveness and grain dustinduced inflammation in the lower respiratory tract. Am J Physiol 1994; 267: L609-L617.

28 Snella MC, Rylander R. Lung cell reactions after inhalation of bacterial lipopolysaccharides. Eur J Respir Dis 1982; 63: 550-557.
29 Elder AC, Finkelstein J, Johnston C, Gelein R, Oberdorster G. Induction of adaptation to inhaled lipopolysaccharide in young and old rats and mice. Inhal Toxicol 2000; 12: 225-243.

30 Beeson PB. With the technical assistance of Elizabeth Roberts. Tolerance to bacterial pyrogens: I. Factors influencing its development. J Exp Med 1947; 86: 29-38.

31 Mueller-Anneling L, O'Neill ME, Doekes G, Thorne PS. Organic dust-induced lung inflammation and the whole blood assay. Am J Respir Crit Care Med 2003; 167: A760.

32 Coffee KA, Halushka PV, Ashton SH, Tempel GE, Wise WC, Cook JA. Endotoxin tolerance is associated with altered GTP-binding protein function. J Appl Physiol 1992; 73: 1008-1013.

33 O'Shaughnessy PT, Achutan C, O'Neill ME, Thorne PS. A small whole-body exposure chamber for laboratory use. Inhal Toxicol 2003; 15: 251-263.

34 Duchaine C, Thorne PS, Meriaux A, Grimard Y, Whitten P, Cormier Y. Comparison of endotoxin exposure assessment by bioaerosol impinger and filter-sampling methods. Appl Environ Microbiol 2001; 67: 2775-2780.

35 Jacobs RR, Boehlecke B, van Hage-Hamsten M, Rylander R. Bronchial reactivity, atopy, and airway response to cotton dust. Am Rev Respir Dis 1993; 148: 19-24.

36 Gioannini TL, Teghanemt A, Zhang D, et al. Isolation of an endotoxin-MD-2 complex that produces Toll-like receptor 4-dependent cell activation at picomolar concentrations. Proc Natl Acad Sci USA 2004; 101: 4186-4191.

37 Lorenz E, Jones M, Wohlford-Lenane C, et al. Genes other than TLR4 are involved in the response to inhaled LPS. Am J Physiol Lung Cell Mol Physiol 2001; 281: L1106-L1114.

38 Yang RB, Mark MR, Gray A, et al. Toll-like receptor-2 mediates lipopolysaccharide-induced cellular signalling. Nature 1998; 395: 284-288.

39 Hermann C, von Aulock S, Graf K, Hartung T. A model of human whole blood lymphokine release for in vitro and ex vivo use. J Immunol Methods 2003; 275: 69-79.

40 Arbour NC, Lorenz E, Schutte BC, et al. TLR4 mutations are associated with endotoxin hyporesponsiveness in humans. Nat Genet 2000; 25: 187-191.

41 Rylander R, Bake B, Fischer JJ, Helander IM. Pulmonary function and symptoms after inhalation of endotoxin. Am Rev Respir Dis 1989; 140: 981-986.

42 Michel O, Duchateau J, Sergysels R. Effect of inhaled endotoxin on bronchial reactivity in asthmatic and normal subjects. J Appl Physiol 1989; 66: 1059-1064.

43 Schins RP, van Hartingsveldt B, Borm PJ. Ex vivo cytokine release from whole blood. A routine method for health effect screening. Exp Toxicol Pathol 1996; 48: 494-496.

44 Rylander R. Health effects of cotton dust exposures. Am J Ind Med 1990; 17: 39-45.

45 Kirchner H, Kleinicke C, Digel W. A whole-blood technique for testing production of human interferon by leukocytes. J Immunol Methods 1982; 48: 213-219.

46 Koyama S, Sato E, Nomura H, et al. The potential of various lipopolysaccharides to release monocyte chemotactic activity from lung epithelial cells and fibroblasts. Eur Respir J 1999; 14: 545-552. 